\title{
Dynamic relationship between precious metals is
}

\author{
Ahmet Sensoy ${ }^{\mathrm{a}, \mathrm{b}, *}$ \\ a Borsa Istanbul, Research Department, 34467 Emirgan, Istanbul, Turkey \\ ${ }^{\mathrm{b}}$ Bilkent University, Department of Mathematics, 06800 Ankara, Turkey
}

\section{A R T I C L E I N F O}

\section{Article history:}

Received 18 June 2013

Received in revised form

6 August 2013

Accepted 9 August 2013

Available online 3 September 2013

\section{JEL classification:}

C58

C61

G01

G11

L61

\section{Keywords:}

Volatility shift contagion

Precious metals

Consistent dynamic conditional correlation

Penalized contrast function

Dynamic equicorrelation

\begin{abstract}
A B S T R A C T
We use a relatively new approach to endogenously detect the volatility shifts in the returns of four major precious metals (gold, silver, platinum and palladium) from 1999 to 2013. We reveal that the turbulent year of 2008 has no significant effect on volatility levels of gold and silver however causes an upward shift in the volatility levels of palladium and platinum. Using the consistent dynamic conditional correlations, we show that precious metals get strongly correlated with each other in the last decade which reduces the diversification benefits across them and indicates a convergence to a single asset class. We endogenously detect the shifts in these dynamic correlation levels and reveal uni-directional volatility shift contagions among precious metals. The results show that gold has a uni-directional volatility shift contagion effect on all other precious metals and silver has a similar effect on platinum and palladium. However, the latter two do not matter in terms of volatility shift contagion. Thus, investors that hedge with precious metals should, in particular, monitor the volatility levels of gold and silver.
\end{abstract}

(c) 2013 Elsevier Ltd. All rights reserved.

\section{Introduction}

Last two decades have witnessed four major international financial crisis with each of them having different causes. The Asian crisis of 1997 started as a result of short-term capital outflows and then spread to many other emerging markets. 1998 Russia crisis started with a chronic fiscal deficit leading to Russian government's default on domestic debt and a panic spread throughout the world financial system. In 2001, the collapse of the dot com stocks triggered a mild economic recession in U.S. and further caused liquidity problems in the international banking sector. And the global crisis of 2008 began with a loss of confidence in the value of securitized mortgages in the U.S., resulted in a liquidity crisis deepened as stock markets worldwide crashed. One of the common points of these crisis is that they are characterized by high volatility and contagion (Markwat et al., 2009). Moreover, many studies reveal that these crises increase

\footnotetext{
${ }^{2}$ The views expressed in this work are those of the authors and do not necessarily reflect those of the Borsa Istanbul or its members.

* Correspondence address: Borsa Istanbul, Research Department, 34467 Emirgan, Istanbul, Turkey. Tel.: +90 53269599 43, +90 21229827 39; fax: +902122982189.

E-mail addresses: ahmet.sensoy@borsaistanbul.com, ahmets@fen.bilkent.edu.tr
}

the correlations between the world's equity markets that remain high for a long time, and thus lower the diversification potential even one constructs a widely internationally diversified portfolio of stocks (Climent and Meneu, 2003; Bayoumi et al., 2007; Gilmore et al., 2008; Diamandis, 2009; Syllignakis and Kouretas, 2011).

High volatility and contagion effect have led investors to consider alternative instruments as a part of their portfolios to be able to diversify away the increasing risk in the stock markets. Thus, the major precious metals i.e. gold, silver, platinum and palladium stepped in as eligible financial assets for portfolio diversification. When, for any reason, the stock markets go through an instable period or worldwide economic uncertainties arise, these precious metals are viewed as safe haven assets by many investors as their values are considered to be more stable than that of other commodities and the stock prices. Besides, the hedging capacity of precious metals due to their low correlation with equity markets makes them even more attractive (Hillier et al., 2006). In addition to policy makers and investors, manufacturers also pay close attention to precious metals as they have important and diversified industrial use in jewelery, electronic, chemical and automotive industries. Therefore, investigating the price dynamics of precious metals is of great interest (Chen, 2010; Mutafoglu et al., 2012). 
The main purpose of this research is to provide an analysis on the volatility shift contagions among precious metals which is defined as a significant change in the co-movement of asset returns between consecutive volatility regimes (Forbes and Rigobon, 2002). Detecting volatility shift contagion among precious metals is of extreme importance. If there is no such a contagion effect then the possibility of risk diversification among these assets increases. On the other hand, if there exists a contagion effect, knowing the contagion direction can help investors (who hold different precious metals in their portfolios) to adjust their asset allocations pro-actively in case of a volatility shift in the precious metal prices.

With this motivation, we will analyze 14 years of data that span from January 1999 to April 2013. ${ }^{1}$ We first detect sudden and gradual changes in the volatility of precious metal returns using a penalized contrast function method of Lavielle (2005) that was previously applied on different financial time series by Lavielle and Teyssiere (2007). Since we endogenously detect the break points, periods of relatively high and low volatility are defined regardless of whether a financial crisis is the true cause.

In the next step, we estimate a consistent dynamic conditional correlation (cDCC) model (Aielli, 2013) to evaluate co-movements between precious metal returns. Then we detect the significant mean shifts in these dynamic correlations. Determining breakdowns in co-movements is highly controversial. Many previous studies have used exogenously identified breaks. However such a choice is usually subject to criticism. We use a similar penalized contrast function method to detect the mean shifts in the correlations, and finally we will analyze if the mean shifts are related to the volatility shifts by comparing the relevant dates.

\section{Literature review}

\section{Detection of volatility shifts in financial time series}

One of the most important stylized facts of the financial time series is the time-varying volatility. The importance of this concept is due to the fact that volatility is crucial for asset pricing, volatility forecasting and financial risk management (Pettenuzzo and Timmermann, 2011). External events such as policy changes and crises may cause temporary (outlier) or permanent (structural break) changes in the structure of volatility. In that case, identification of volatility break (shift) points is important to determine the true effect of external events and for proper modelingforecasting. Moreover, ignoring the existence of volatility shifts can result as spurious IGARCH or long memory effect (Mikosch and Starica, 2004).

In the literature, the most widely used methodology to endogenously detect the volatility shifts is the ICSS algorithm (based on the cumulative sum-CUSUM of squared series), which was developed by Inclan and Tiao (1994) and made well known in the financial literature by Aggarwal et al. (1999) and later by Ewing and Malik (2005). However, the weakness of this method comes from its assumptions that the disturbances are independent and normally distributed; two conditions that could be considered unrealistic for financial time series. Bacmann and Dubois (2002) point out that the behavior of the ICSS algorithm is questionable under the presence of conditional heteroskedasticity and it tends to overstate the number of actual structural breaks in variance. They show that one way to get over this problem is by filtering the return series by a GARCH $(1,1)$ model, and applying the ICSS

\footnotetext{
${ }^{1}$ Fig. 1 shows the price series of precious metals from January 1999 to April 2013. In the early 2000s, precious metal markets entered into a new phase where a continuous upward trend of prices had been observed until the October 2008 crash.
}

algorithm to the standardized residuals. They conclude that structural breaks in unconditional variance are less frequent than it was shown previously, but some studies conclude that after such a procedure, overestimation is still observed. ${ }^{2}$ Later, numerous researches proposed modified versions of this methodology (which are all based on the CUSUM test) that accommodate the non-normality and serial dependence (Kokoszka and Leipus, 2000; Andreou and Ghysels, 2002; Sanso et al., 2004; Deng and Perron, 2008). However, although their increased robustness, Xu (2013) states that these tests are constructed without considering any explicit alternative hypotheses which make them open to be criticized for having low power in practice.

In this study, unlike several others in the literature, we choose to use a novel methodology of Lavielle (2005). It uses a penalized contrast to simultaneously detect the number of change points in the volatility and their locations. One of its advantages is that the variables are not necessarily normally distributed or independent. Its superiority to the ICSS method and the KL method (Kokoszka and Leipus, 2000) and its consistency under the presence of outliers and weak and strong dependency have been demonstrated by Lavielle and Teyssiere (2007) using empirical and simulated data.

\section{Volatility shifts in precious metals and spillovers}

There is an extensive literature analyzing volatility spillovers between stock markets and commodity markets (see Mensi et al., 2013, and the references therein), or between different commodity classes (see Nazlioglu et al., 2013; Ewing and Malik, 2013 and the references therein), however, the link between precious metals themselves has received far less attention. Moreover, some of the findings contradict with each other.

Hammoudeh et al. (2010) examine the conditional volatility and correlation dependency for the four major precious metals and they find that almost all of them are weakly responsive to news spilled over from other metals in the short run. A similar conclusion comes from Batten et al. (2010); authors conclude that there is evidence of volatility feedback between the precious metals. Furthermore, they claim that precious metals are too distinct to be considered as a single asset class.

On the contrary, Morales and Andreosso-O'Callaghan (2011) find that in terms of volatility spillover, an asymmetric effect is observed; gold tends to dominate the markets and the evidence favoring the case of the other precious metals influencing the gold market is weak.

Considering volatility shifts, Cochran et al. (2012) state that events during the post-September 2008 period increased the volatility in gold, platinum, and silver returns. However, Vivian and Wohar (2012) did not find evidence of volatility breaks in precious metal returns during the recent financial crisis suggesting that volatility was not exceptionally high during the 2008 crisis compared to its level between 1985 and 2010.

As understood, the literature actually presents mixed results.

\section{Methodology}

\section{Detection of the mean and volatility shifts}

As mentioned before, we will use the method of Lavielle (2005) to detect mean shifts in the dynamic correlation levels and volatility shifts in the precious metal returns. The methodology

\footnotetext{
${ }^{2}$ For another study that shows the probable spurious results of the ICSS algorithm, see Kumar and Maheswaran (2013).
} 

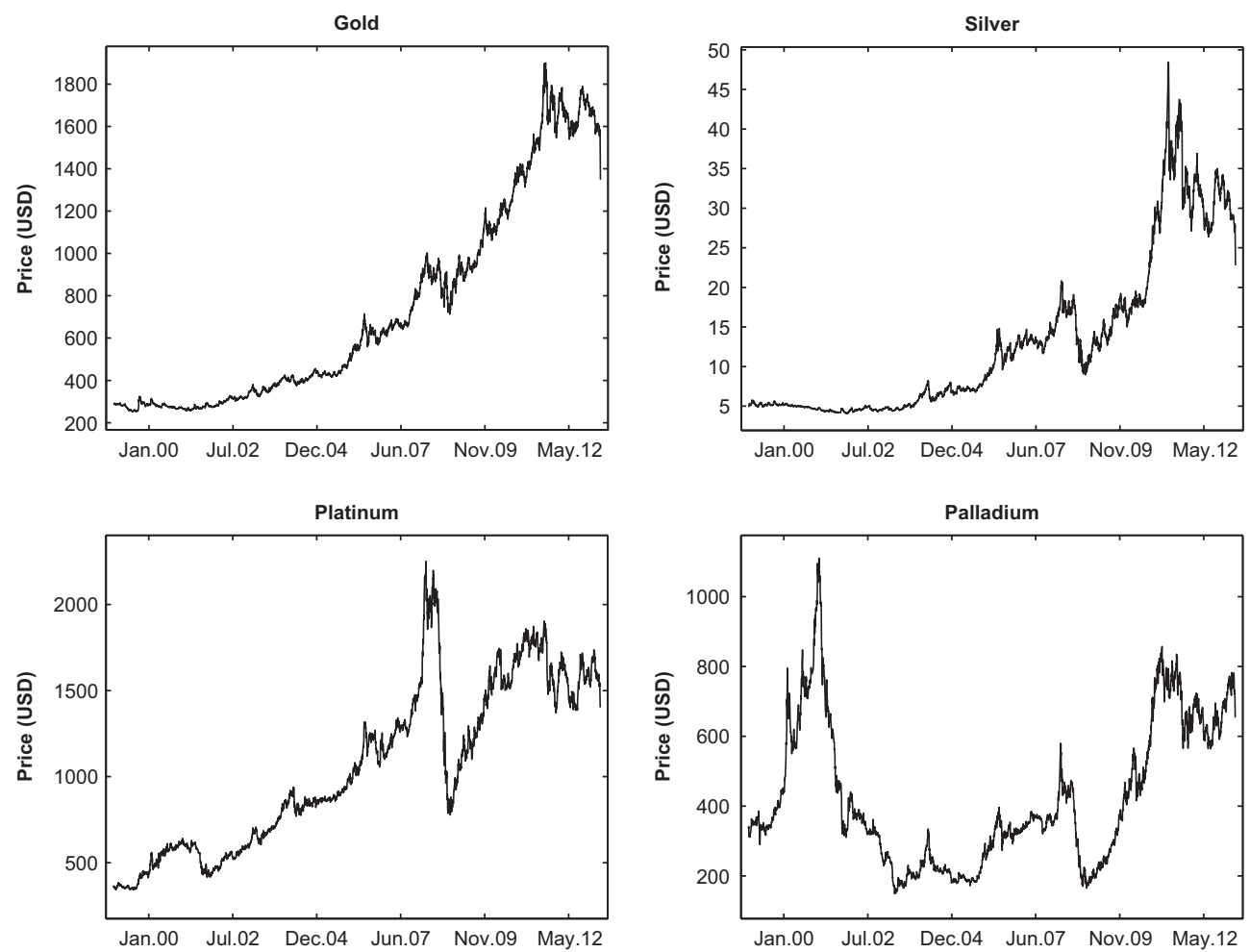

Fig. 1. Price series of major precious metals between January 1999 and April 2013.

can be summarized as follows: we consider a sequence of random variables $Y_{1}, \ldots, Y_{n}$ that take values in $\mathbb{R}^{p}$. Assume that $\theta \in \Theta$ is a parameter denoting the characteristics of the $Y_{i}$ 's that changes abruptly and remains constant between two changes. The change occurs at some instants $\tau_{1}^{\star}<\tau_{2}^{\star}<\cdots<\tau_{K^{\star}-1}^{\star}$. Here $K^{\star}-1$ is the number of change points hence we have $K^{\star}$ number of segments. ${ }^{3}$

Now, let $K$ be some integer and let $\boldsymbol{\tau}=\left(\tau_{1}, \tau_{2}, \ldots, \tau_{K-1}\right)$ be a sequence of integers satisfying $0<\tau_{1}<\tau_{2}<\cdots<\tau_{K-1}<n$. For any $1 \leq k \leq K$, let $U\left(Y_{\tau_{k-1}+1}, \ldots, Y_{\tau_{k}} ; \theta\right)$ be a contrast function useful for estimating the unknown true value of the parameter in the segment $k$; i.e. the minimum contrast estimate $\hat{\theta}\left(Y_{\tau_{k-1}+1}, \ldots, Y_{\tau_{k}}\right)$, computed on segment $k$ of $\boldsymbol{\tau}$, is defined as a solution of the following minimization problem:

$U\left(Y_{\tau_{k-1}+1}, \ldots, Y_{\tau_{k}} ; \hat{\theta}\left(Y_{\tau_{k-1}+1}, \ldots, Y_{\tau_{k}}\right)\right) \leq U\left(Y_{\tau_{k-1}+1}, \ldots, Y_{\tau_{k}} ; \theta\right), \quad \forall \theta \in \Theta$,

For any $1 \leq k \leq K$, let $G$ be

$G\left(Y_{\tau_{k-1}+1}, \ldots, Y_{\tau_{k}}\right)=U\left(Y_{\tau_{k-1}+1}, \ldots, Y_{\tau_{k}} ; \hat{\theta}\left(Y_{\tau_{k-1}+1}, \ldots, Y_{\tau_{k}}\right)\right)$

Then define the contrast function $J(\boldsymbol{\tau}, \boldsymbol{y})$ as

$J(\boldsymbol{\tau}, \boldsymbol{y})=\frac{1}{n} \sum_{k=1}^{K} G\left(Y_{\tau_{k-1}+1}, \ldots, Y_{\tau_{k}}\right)$

where $\tau_{0}=0$ and $\tau_{k}=n$. When true number $K^{\star}$ segments are known, for any $1 \leq k \leq K^{\star}$, the sequence $\hat{\boldsymbol{\tau}}_{n}$ of change point instants that minimizes this kind of contrast has the property that

$\operatorname{Pr}\left(\left|\hat{\tau}_{n, k}-\tau_{k}^{\star}\right|>\delta\right) \rightarrow 0$, when $\delta \rightarrow \infty$ and $n \rightarrow \infty$

In particular, this result holds for weak or strong dependent processes.

\footnotetext{
${ }^{3} \star$ is used to denote the true value.
}

Table 1

Descriptive statistics of the raw returns of precious metals from $02 / 01 / 1999$ to $15 / 04 / 2013$.

\begin{tabular}{lcccc}
\hline & \multicolumn{1}{l}{ Gold } & \multicolumn{1}{l}{ Silver } & Platinum & \multicolumn{1}{l}{ Palladium } \\
\hline Mean & 0.000415 & 0.000405 & 0.000364 & 0.000184 \\
Median & 0.000494 & 0.001315 & 0.000579 & 0.000002 \\
Max & 0.102451 & 0.131802 & 0.087421 & 0.115235 \\
Min & -0.09512 & -0.20385 & -0.10259 & -0.16998 \\
Std. dev. & 0.011513 & 0.019621 & 0.014660 & 0.021767 \\
Kurtosis & 10.20349 & 14.12045 & 8.124921 & 6.944922 \\
Skewness & -0.11514 & -1.34284 & -0.53629 & -0.41625 \\
\hline
\end{tabular}

We consider the following model:

$Y_{i}=\mu_{i}+\sigma_{i} \varepsilon_{i}, \quad 1 \leq i \leq n$

where $\left(\varepsilon_{i}\right)$ is a sequence zero-mean random variables with unit variance.

In the case of detecting changes in the mean, we assume that $\left(\mu_{i}\right)$ is a piecewise constant sequence and $\left(\sigma_{i}\right)$ is a constant sequence. Now, even if $\left(\varepsilon_{i}\right)$ is not normally distributed, a Gaussian log-likelihood can be used to define the contrast function. Let

$U\left(Y_{\tau_{k-1}+1}, \ldots, Y_{\tau_{k}} ; \mu\right)=\sum_{i=\tau_{k-1}+1}^{\tau_{k}}\left(Y_{i}-\mu\right)^{2}$

Then,

$G\left(Y_{\tau_{k-1}+1}, \ldots, Y_{\tau_{k}}\right)=\sum_{i=\tau_{k-1}+1}^{\tau_{k}}\left(Y_{i}-\bar{Y}_{\tau_{k-1}+1: \tau_{k}}\right)^{2}$

where $\bar{Y}_{\tau_{k-1}+1: \tau_{k}}$ is the empirical mean of $\left(Y_{\tau_{k-1}+1}, \ldots, Y_{\tau_{k}}\right)$.

To detect the changes in the volatility, we take $\left(\mu_{i}\right)$ as a constant sequence and $\left(\sigma_{i}\right)$ as a piecewise constant sequence. As before, even if $\left(\varepsilon_{i}\right)$ is not normally distributed, a Gaussian log-likelihood 

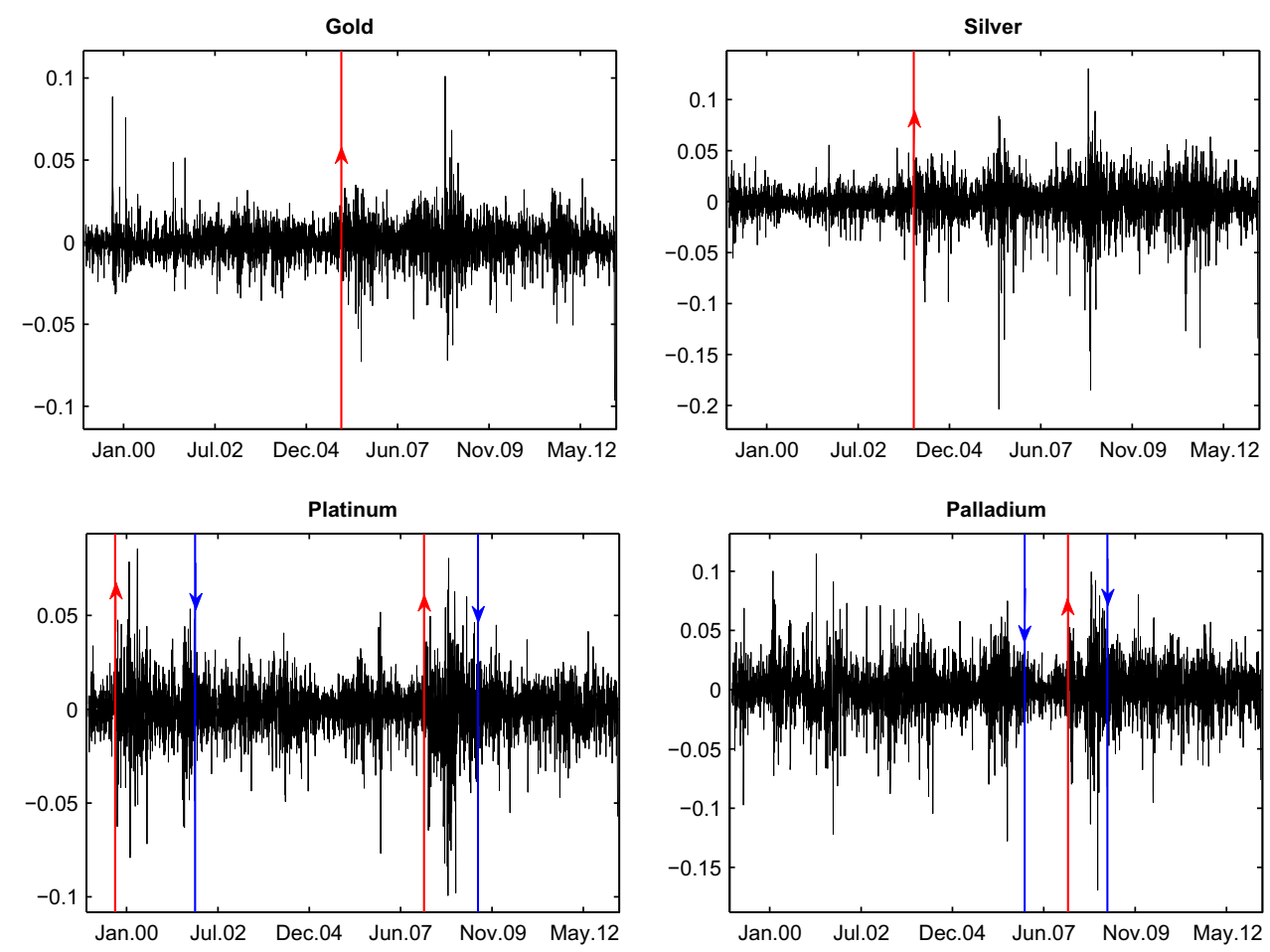

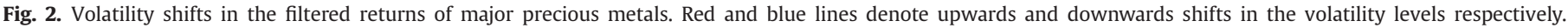
(For interpretation of the references to color in this figure caption, the reader is referred to the web version of this article.)

can be used to define the contrast function. Let $\mu=\mu_{i}=\ldots=\mu_{\tau_{k^{\star}}}$ and

$U\left(Y_{\tau_{k-1}+1}, \ldots, Y_{\tau_{k}} ; \sigma^{2}\right)=\left(\tau_{k}-\tau_{k-1}\right) \log \left(\sigma^{2}\right)+\frac{1}{\sigma^{2}} \sum_{i=\tau_{k-1}+1}^{\tau_{k}}\left(Y_{i}-\mu\right)^{2}$

Then,

$G\left(Y_{\tau_{k-1}+1}, \ldots, Y_{\tau_{k}}\right)=\left(\tau_{k}-\tau_{k-1}\right) \log \left(\hat{\sigma}_{\tau_{k-1}+1: \tau_{k}}^{2}\right)$

where

$\hat{\sigma}_{\tau_{k-1}+1: \tau_{k}}^{2}=\frac{1}{\tau_{k}-\tau_{k-1}} \sum_{i=\tau_{k-1}+1}^{\tau_{k}}\left(Y_{i}-\bar{Y}\right)^{2}$

is the empirical variance of $\left(Y_{\tau_{k-1}+1}, \ldots, Y_{\tau_{k}}\right)$ and $\bar{Y}$ is the empirical mean of $Y_{1}, \ldots, Y_{n}$.

If changes affect both the mean and the volatility, then a contrast function based on a Gaussian log-likelihood is

$G\left(Y_{\tau_{k-1}+1}, \ldots, Y_{\tau_{k}}\right)=\left(\tau_{k}-\tau_{k-1}\right) \log \left(\hat{\sigma}_{\tau_{k-1}+1: \tau_{k}}^{2}\right)$

where

$\hat{\sigma}_{\tau_{k-1}+1: \tau_{k}}^{2}=\frac{1}{\tau_{k}-\tau_{k-1}} \sum_{i=\tau_{k-1}+1}^{\tau_{k}}\left(Y_{i}-\bar{Y}_{\tau_{k-1}+1: \tau_{k}}\right)^{2}$

Finding the number of shift points

When the number of shift points is unknown, it is estimated by minimizing a penalized version of $J(\boldsymbol{\tau}, \boldsymbol{y})$. For any sequence of change point instants $\tau$, let pen $(\tau)$ be a function of $\tau$ that increases with the number $K(\boldsymbol{\tau})$ of segments of $\boldsymbol{\tau}$. Then, let $\hat{\boldsymbol{\tau}}_{n}$ be the sequence of change point instants that minimizes

$F(\boldsymbol{\tau})=J(\boldsymbol{\tau}, \boldsymbol{y})+\operatorname{\varphi pen}(\boldsymbol{\tau})$

where $\varphi$ is a function of $n$ that goes to zero at an appropriate rate as $n$ goes to infinity. The estimated number of segments $K\left(\hat{\boldsymbol{\tau}}_{n}\right)$
Table 2

Volatility level shift dates of precious metal returns.

\begin{tabular}{ll}
\hline Date & Volatility \\
\hline Gold & \\
$29 / 11 / 2005$ & Up \\
Silver & \\
$02 / 01 / 2004$ & Up \\
Platinum & \\
$24 / 09 / 1999$ & Up \\
20/11/2001 & Down \\
$23 / 01 / 2008$ & Up \\
$08 / 07 / 2009$ & Down \\
Palladium & \\
$30 / 11 / 2006$ & \\
$31 / 01 / 2008$ & Down \\
$23 / 02 / 2009$ & Up \\
\hline
\end{tabular}

converges in probability to $K^{\star}$. The proper $\operatorname{pen}(\tau)$ and the penalization parameter $\varphi$ are chosen according to Lavielle (2005). ${ }^{4}$

\section{Consistent dynamic conditional correlation}

The dynamic correlations between fluctuations in the precious metal prices will be obtained by the cDCC model of Aielli (2013). First, we start by reviewing the DCC modeling (Engle, 2002) approach. Denote by $y_{t}=\left[y_{1, t}, \ldots, y_{M, t}\right]^{\prime}$ the $M \times 1$ vector of the asset returns at time $t$, and assume that $E_{t-1}\left[y_{t}\right]=0$ and $E_{t-1}\left[y_{t} y_{t}^{\prime}\right]=H_{t}$, where $E_{t}[\cdot]$ is the conditional expectation on

\footnotetext{
${ }^{4}$ For further details, refer to Lavielle (2005) and Lavielle and Teyssiere (2007).
} 

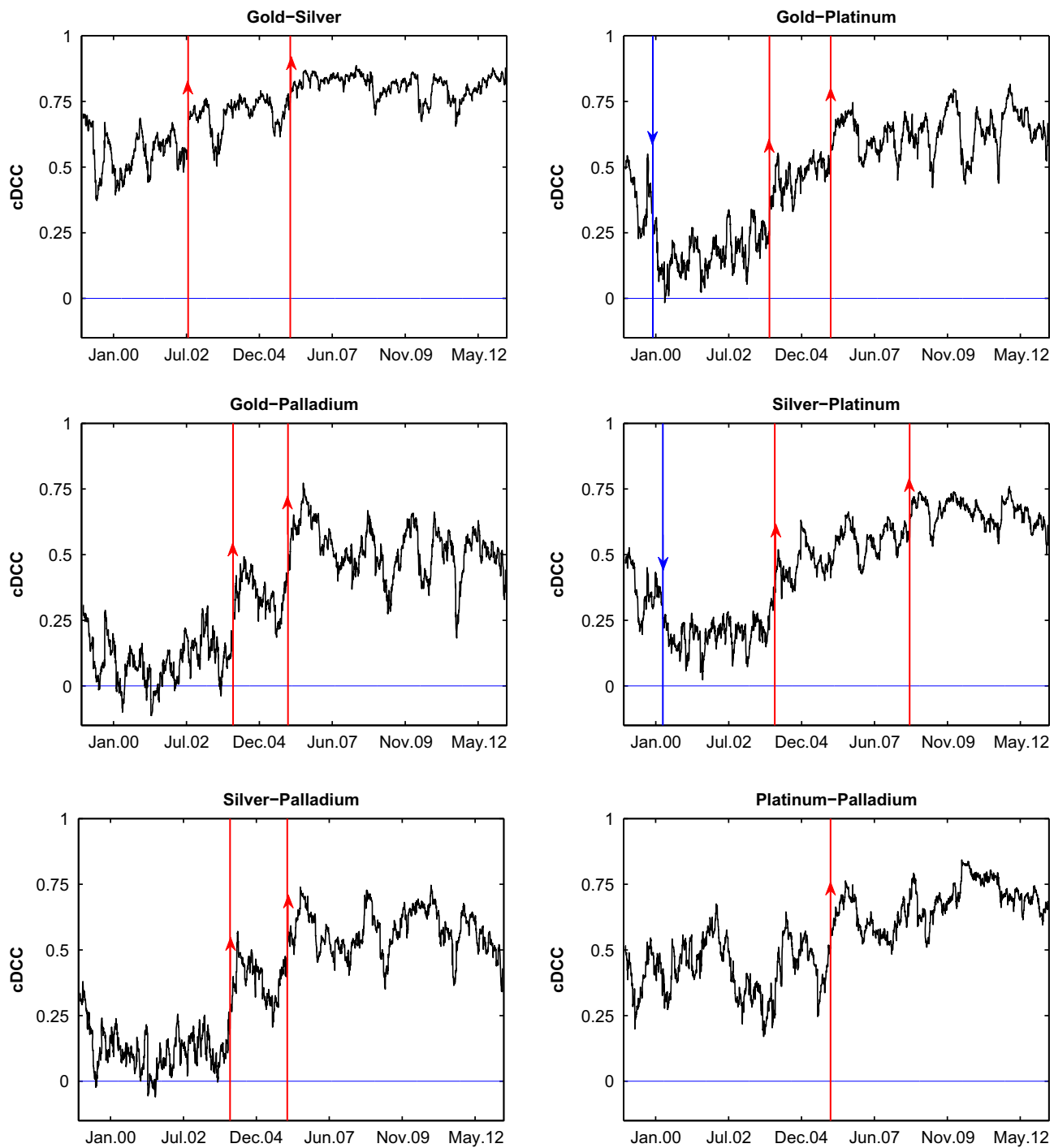

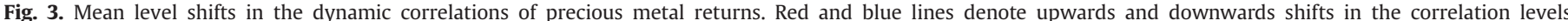
respectively. (For interpretation of the references to color in this figure caption, the reader is referred to the web version of this article.)

$y_{t}, y_{t-1}, \ldots$. The asset conditional covariance matrix can be written as

$H_{t}=D_{t}^{1 / 2} R_{t} D_{t}^{1 / 2}$

where $R_{t}=\left[\rho_{i j, t}\right]$ is the asset conditional correlation matrix and the diagonal matrix of the asset conditional variances is given by $D_{t}=\operatorname{diag}\left(h_{1, t}, \ldots, h_{M, t}\right)$. By construction, $R_{t}$ is the conditional covariance matrix of the asset standardized returns that is $E_{t-1}\left[\varepsilon_{t} \varepsilon_{t}^{\prime}\right]=R_{t}$, where $\varepsilon_{t}=\left[\varepsilon_{1, t}, \ldots, \varepsilon_{M, t}\right]$, and $\varepsilon_{i, t}=y_{i, t} / \sqrt{h_{i, t}}$. Engle (2002) models the right hand side of Eq. (14) rather than $H_{t}$ directly

$R_{t}=\left\{Q_{t}^{*}\right\}^{-1 / 2} Q_{t}\left\{Q_{t}^{*}\right\}^{-1 / 2}$,

$Q_{t}=(1-\alpha-\beta) S+\alpha \varepsilon_{t-1} \varepsilon_{t-1}{ }^{\prime}+\beta Q_{t-1}$,

where $Q_{t} \equiv\left[q_{i j, t}\right], S \equiv\left[s_{i j}\right], Q_{t}^{*}=\operatorname{diag}\left\{Q_{t}\right\}$ and $\alpha, \beta$ are scalars. The resulting model is called DCC.

The cDCC model assumes that the correlation driving process is

$Q_{t}=(1-\alpha-\beta) S+\alpha\left\{Q_{t-1}^{* 1 / 2} \varepsilon_{t-1} \varepsilon_{t-1}^{\prime} Q_{t-1}^{* 1 / 2}\right\}+\beta Q_{t-1}$
Explicitly, the correlation is defined as

$\rho_{i j, t}=\frac{\omega_{i j, t-1}+\alpha \varepsilon_{i, t-1} \varepsilon_{j, t-1}+\beta \rho_{i j, t-1}}{\sqrt{\left\{\omega_{i i, t-1}+\alpha \varepsilon_{i, t-1}^{2}+\beta \rho_{i i, t-1}\right\}\left\{\omega_{j j, t-1}+\alpha \varepsilon_{j, t-1}^{2}+\beta \rho_{j j, t-1}\right\}}}$

where $\omega_{i j, t} \equiv(1-\alpha-\beta) s_{i j} / \sqrt{q_{i i, t} q_{j j, t}}$. Since $E_{t-1}\left[\varepsilon_{i, t} \varepsilon_{j, t}\right]=\rho_{i j, t}$, the formula for $\rho_{i j, t}$ combines a sort of GARCH devices for the relevant past values and innovations into a correlation-like ratio. The parameters $\alpha$ and $\beta$ are the dynamic parameters of the correlation GARCH devices. The time-varying intercept $\omega_{i j, t}$ can be seen as an ad hoc correction required for purposes of tractability (Aielli, 2013).

\section{Data and results}

We consider the daily spot prices of gold, silver, platinum and palladium quoted as US dollars per troy ounce from 02/01/1999 to $15 / 04 / 2013$ where the source of data is Bloomberg. Spot prices for platinum and palladium are valid for those in plate or ingot form with a minimum purity of $99.95 \%$ (Table 1 ).

Before applying any methodologies, all raw return data are filtered with an $\operatorname{ARMA}(p, q)$ process where the optimal lag 
Table 3

Shift dates of the dynamic correlation levels between precious metal returns.

\begin{tabular}{ll}
\hline Date & Mean \\
\hline Gold-silver & \\
$24 / 07 / 2002$ & Up \\
$04 / 01 / 2006$ & Up \\
Gold-platinum & \\
$09 / 12 / 1999$ & Down \\
$18 / 11 / 2003$ & Up \\
$13 / 12 / 2005$ & Up \\
Gold-palladium & \\
$29 / 01 / 2004$ & \\
$07 / 12 / 2005$ & Up \\
Silver-platinum & Up \\
$11 / 04 / 2000$ & \\
$23 / 01 / 2004$ & Down \\
$13 / 08 / 2008$ & Up \\
Silver-palladium & Up \\
$29 / 01 / 2004$ & \\
$04 / 01 / 2006$ & Up \\
Platinum-palladium & Up \\
$13 / 12 / 2005$ & \\
\hline
\end{tabular}

selections are based on Bayesian information criteria. ${ }^{5}$ In the cDCC estimation, we use a GJR-GARCH $(1,1)$ process for an additional weight to negative returns. ${ }^{6}$ Fig. 2 presents a visual representation of the volatility shifts in the filtered returns and the exact shift dates are given in Table 2.

Table 2 states that the turbulent year of 2008 has no effect on volatility levels of gold and silver, however, in early 2008 a significant upwards shift is observed in the volatility levels of palladium and platinum that last more than a year. In terms of volatility shift, the 2008 crisis has a differentiated effect on precious metals.

The next thing to consider is the cDCCs between each pair of precious metal returns. We have to point out the major limitations and drawbacks of existing empirical literature on financial contagion which we will overcome in our study by the cDCC approach (Chiang et al., 2007).

First, since contagion is defined as a significant increase in cross correlations, it requires a time-varying observable correlation level so that we can reveal if there is a dynamic increment or not. This problem is directly solved by CDCC modeling as it allows us to detect dynamic responses in correlations to news and innovations.

Second, there is a heteroskedasticity problem when measuring correlations, caused by volatility increases during the crisis. This is not a problem in our study since cDCC model estimates correlation coefficients of the standardized residuals and thus accounts for heteroskedasticity directly.

Fig. 3 presents a visual representation of the mean shifts in the cDCCs and the exact shift dates are given in Table 3.

Combining Tables 2 and 3 tells us the following: within at most one business month after the upward volatility shift in gold returns (29/11/2005), mean level of all dynamic correlations between gold and other precious metals shifts upwards significantly (indeed all bilateral correlation levels shift up!). However, no other precious metal has such an effect on the correlation levels between gold and itself, suggesting that gold has a uni-directional volatility shift contagion effect on all precious metals. Similarly, we

\footnotetext{
${ }^{5}(p, q)$ is found to be $(0,0)$ for gold and silver and $(1,1)$ for platinum and palladium.

${ }^{6}$ Parameters for the GJR-GARCH and the cDCC process are given in Appendix B.
}

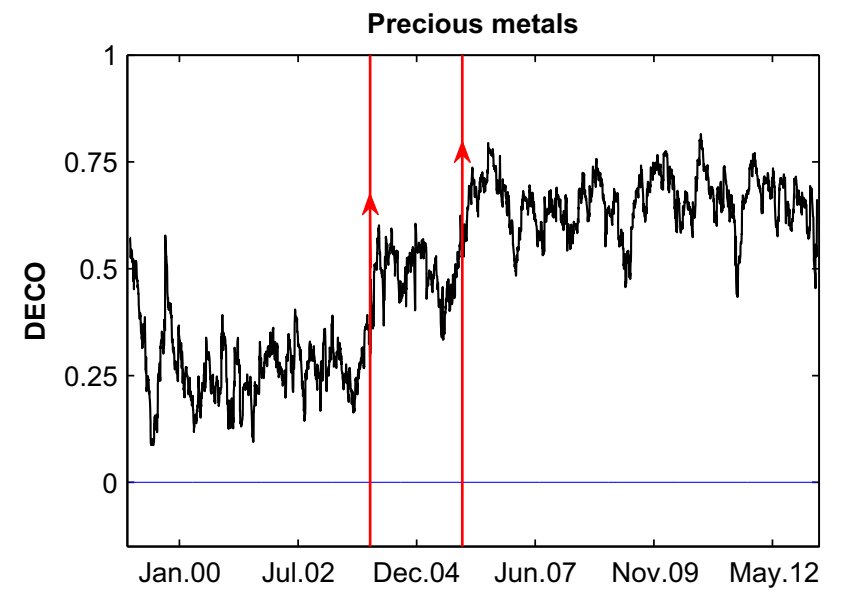

Fig. 4. Dynamic equicorrelation between precious metal returns. Red lines denote the upwards shifts in the equicorrelation level. (For interpretation of the references to color in this figure caption, the reader is referred to the web version of this article.)

Table 4

Volatility shift contagion table.

\begin{tabular}{llllll}
\hline & Gold & Silver & Platinum & Palladium & Precious metals \\
\hline Gold $\rightarrow$ & - & YES & YES & YES & YES \\
Silver $\rightarrow$ & NO & - & YES & YES & YES \\
Platinum $\rightarrow$ & NO & NO & - & NO & NO \\
Palladium $\rightarrow$ & NO & NO & NO & - & NO \\
\hline
\end{tabular}

notice that within at most one business month after the upward volatility shift in silver returns (02/01/2004), mean level of the dynamic correlations between silver-platinum and silver-palladium shifts upward significantly. On the other hand, volatility shifts in platinum and palladium returns do not have such a shifting effect on the correlation levels between silver and themselves suggesting that silver has a uni-directional volatility shift contagion effect on other precious metals except gold. Finally, one can easily see that volatility shifts in returns of platinum and palladium have no effect on the dynamic correlation levels between themselves, we thus conclude that they have no volatility shift contagion effect on any other precious metal.

There is also a remarkable increase in each bilateral correlation in the last decade. On the contrary to the claim of Batten et al. (2010), we believe that the precious metals will be a single asset class in near future.

Last thing to consider is the co-movement degree of precious metals as a whole. In that manner, we use the dynamic equicorrelation (DECO) model of Engle and Kelly (2012) which helps us to represent the co-movement degree of a group of assets with a single time-varying correlation coefficient (see Fig. 4). ${ }^{7}$

According to our penalized contrast methodology, DECO significantly shifts up on $02 / 01 / 2004$ and $01 / 12 / 2005$, where the first date is exactly the date of upward volatility shift in silver returns, and the latter is two business days after the upward volatility shift in gold returns. We, thus, can conclude that only gold and silver have volatility shift contagion effects on precious metals. Fig. 4 also shows how diversification benefits across precious metals were significantly reduced in the last decade.

\footnotetext{
${ }^{7}$ See Appendix A and Engle and Kelly (2012) for further details.
} 
Table B1

GJR-GARCH parameters for the filtered returns and the driving parameters of cDCC between precious metals.

\begin{tabular}{|c|c|c|c|c|}
\hline & \multicolumn{4}{|c|}{ GJR-GARCH } \\
\hline & $c \times 10^{4}$ & \multicolumn{2}{|l|}{$a$} & $b$ \\
\hline Gold & $\begin{array}{l}0.024678 \\
(0.0533)\end{array}$ & \multirow{4}{*}{$\begin{array}{l}0.087037 \\
(0.0017) \\
0.098193 \\
(0.0003) \\
0.099746 \\
(0.0000) \\
0.081482 \\
(0.0000)\end{array}$} & $\begin{array}{l}-0.038804 \\
(0.0524)\end{array}$ & $\begin{array}{l}0.916200 \\
(0.0000)\end{array}$ \\
\hline Silver & $\begin{array}{l}0.013117 \\
(0.1317)\end{array}$ & & $\begin{array}{l}-0.049609 \\
(0.0044)\end{array}$ & $\begin{array}{l}0.930790 \\
(0.0000)\end{array}$ \\
\hline Platinum & $\begin{array}{l}0.031059 \\
(0.0082)\end{array}$ & & $\begin{array}{l}-0.031467 \\
(0.0383)\end{array}$ & $\begin{array}{l}0.903378 \\
(0.0000)\end{array}$ \\
\hline \multirow[t]{3}{*}{ Palladium } & $\begin{array}{l}0.082627 \\
(0.0245)\end{array}$ & & $\begin{array}{l}0.005266 \\
(0.7582)\end{array}$ & $\begin{array}{l}0.901561 \\
(0.0000)\end{array}$ \\
\hline & & \multicolumn{2}{|c|}{$\mathrm{cDCC}$} & \\
\hline & & \multicolumn{2}{|l|}{$\alpha$} & $\beta$ \\
\hline \multicolumn{2}{|l|}{ Gold-silver } & \multicolumn{2}{|c|}{$\begin{array}{l}0.035362 \\
(0.0000)\end{array}$} & $\begin{array}{l}0.961141 \\
(0.0000)\end{array}$ \\
\hline \multicolumn{2}{|l|}{ Gold-platinum } & \multicolumn{2}{|c|}{$\begin{array}{l}0.041675 \\
(0.0000)\end{array}$} & $\begin{array}{l}0.951977 \\
(0.0000)\end{array}$ \\
\hline \multicolumn{2}{|l|}{ Gold-palladium } & \multicolumn{2}{|c|}{$\begin{array}{l}0.019120 \\
(0.0080)\end{array}$} & $\begin{array}{l}0.979318 \\
(0.0000)\end{array}$ \\
\hline \multicolumn{2}{|l|}{ Silver-platinum } & \multicolumn{2}{|c|}{$\begin{array}{l}0.018476 \\
(0.0135)\end{array}$} & $\begin{array}{l}0.980531 \\
(0.0000)\end{array}$ \\
\hline \multicolumn{2}{|l|}{ Silver-palladium } & \multicolumn{2}{|c|}{$\begin{array}{l}0.012794 \\
(0.0034)\end{array}$} & $\begin{array}{l}0.986681 \\
(0.0000)\end{array}$ \\
\hline Platinum-palladium & & \multicolumn{2}{|c|}{$\begin{array}{l}0.022854 \\
(0.0009)\end{array}$} & $\begin{array}{l}0.975370 \\
(0.0000)\end{array}$ \\
\hline
\end{tabular}

GJR-GARCH is estimated by $\sigma_{t}^{2}=c+\left(a+g I_{\varepsilon_{t-1}<0}\right) \varepsilon_{t-1}^{2}+b \sigma_{t-1}^{2}$.

CDCC process is driven by $Q_{t}=(1-\alpha-\beta) S+\alpha\left\{Q_{t-1}^{* 1 / 2} \varepsilon_{t-1} \varepsilon_{t-1} Q_{t-1}^{* 1 / 2}\right\}+\beta Q_{t-1}$. For a more precise estimation, each pairwise dynamic correlation is calculated separately thus, we have different driving parameters $\alpha$ and $\beta$ for each pair of precious metals.

The values in the parentheses are the $p$-values obtained from robust standard errors

A summary of our findings on volatility shift contagion structure is presented in Table 4.

\section{Discussion and conclusion}

The catastrophic effects of the recent financial crisis reshaped the understanding of portfolio diversification. Now, gold, silver, platinum and palladium serve as alternative investment instruments that are important more than ever and the increase in demand for their economic uses is noteworthy. This deepens the interest of investors, portfolio and risk managers, manufacturers and policy makers to understand better the dynamics of the precious metal prices.

In this study, we endogenously detect sudden and gradual shifts in the volatility levels of the four major precious metal returns (obtained from spot USD prices) in the last 14 years by a relatively novel methodology. We reveal that the turbulent year of 2008 has no significant effect on volatility levels of gold and silver however volatility levels of palladium and platinum significantly shift upwards in early 2008 and stay at their high levels for more than a year.

Later, we analyzed the consistent dynamic conditional correlations of precious metal returns. In general, bilateral correlations in the late 1990s are relatively low ${ }^{8}$ but get higher in the mid 2000s and stay at their high levels since then. Such a situation reveals that diversification benefits to investors across precious metals were significantly reduced in the last decade.

Considering the distinct volatility shift dates of the precious metal prices, our findings are in parallel to those of Batten et al.

\footnotetext{
${ }^{8}$ For example Kearney and Lombra (2009) look for reasons regarding the low correlation between gold and platinum prices in the 1990s.
}

(2010) where authors find only limited evidence for the same macroeconomic factors jointly influencing the volatility processes of the four precious metal price series. However, in contrast to the argument of the authors, such a finding is insufficient to state that precious metals are too distinct to be considered as a single asset class, or represented by a single index. Indeed, based on the drastically increased correlation levels among them (see Figs. 3 and 4), we believe that the precious metals may be classified as a single asset class in the future. This situation also suggests not to use different precious metals for portfolio diversification (which indirectly objects to the conclusion of Jain and Ghosh (2013) where authors state that the relative independence of platinum and silver can be exploited to make a risk diversifying portfolio that provides superior risk adjusted returns).

We have to point out that our argument of converging to a single asset class strongly depends on the claim that the increased correlation will at least be preserved in the future. Due the fact that macroeconomic uncertainty is a major cause for investment in commodities, one could argue that the correlations between precious metals may decrease according to changes in monetary policies and/or increased growth in the world economy. However, we have to remind that our data set spans from 1999 to 2013 , which witnesses not only major global crises but also the periods with highest economic growths for many countries and severe changes in monetary policies. Throughout this time period, the dynamic correlations display downward movements from time to time, however, their levels never shift down and only shift up. ${ }^{9}$ This situation naturally suggests an asymmetric response of the dynamic correlations to exogenous factors which motivates our controversial claim of the single asset class.

\footnotetext{
${ }^{9}$ An upward level shift is observed at least once for each dynamic bilateral correlation and equicorrelation (see Figs. 3 and 4).
} 
In the next part, we endogenously detect the significant shifts in the dynamic correlation levels between precious metal returns. Empirical evidence suggests that there exists uni-directional volatility shift contagions among precious metals. ${ }^{10}$ In particular, gold has a volatility shift contagion effect on all precious metals but no others has such an effect on gold. Similarly, silver has a unidirectional volatility shift contagion effect on platinum and palladium, whereas platinum and palladium found to have no volatility shift contagion effect on any others. The reason for this picture can be explained as follows: gold has historically been a store of value and a medium of exchange until the end of the Bretton Woods system. Even in the post Bretton Woods, gold has been considered as an investment instrument by individuals and as international reserve currency by governments. Similarly, silver has also been considered as a store of value and for monetary exchange in history. Thus, volatility shifts in prices of these two highly important metals may cause abrupt increases in the correlations. However, investors have started to buy and hold platinum and palladium as an alternative to gold and silver recently. This may create an insensitivity in the correlation dynamics to the volatility shifts in platinum and palladium prices.

Considering the investors that hold different precious metals in their portfolios, results suggest that they should, in particular, monitor the volatility levels in gold and silver prices as the shifts in their volatilities significantly increase the correlations between precious metals. We believe that these findings are of importance and will be helpful for portfolio managers and investors.

\section{Appendix A. Dynamic equicorrelation (DCC-DECO)}

Engle and Kelly (2012) suggest modeling $\rho_{t}$ by using the cDCC specification to generate the conditional correlation matrix $Q_{t}$ and then taking the mean of its off-diagonal elements as a simplifying procedure to decrease the estimation time. This approach is termed the Dynamic Equicorrelation (DCC-DECO) model, and the scalar equicorrelation is formally defined by

$\rho_{t}^{D E C O}=\frac{2}{n(n-1)} \sum_{i=1}^{n-1} \sum_{j=i+1}^{n} \frac{q_{i j, t}}{\sqrt{q_{i i, t} q_{j j, t}}}$

where $q_{i j, t}$ is the $(i, j)^{\text {th }}$ element of the matrix $Q_{t}$ from the cDCC model. This scalar equicorrelation is then used to create the conditional correlation matrix

$R_{t}=\left(1-\rho_{t}\right) I_{n}+\rho_{t} J_{n}$

where $J_{n}$ is the $n \times n$ matrix of ones and $I_{n}$ is the $n$-dimensional identity matrix.

\section{Appendix B. Estimation results}

GJR-GARCH parameters and driving parameters of cDCC are given in Table B1.

\section{References}

Aggarwal, R., Inclan, C., Leal, R., 1999. Volatility in emerging stock markets. Journa of Financial and Quantitative Analysis 34, 33-55.

Aielli, G.P. 2013. Dynamic conditional correlation: on properties and estimation, Journal of Business \& Economic Statistics 31, 282-299. 〈http://dx.doi.org/10. 1080/07350015.2013.771027).

Andreou, E., Ghysels, E., 2002. Detecting multiple breaks in financial market volatility dynamics. Journal of Applied Econometrics 17, 579-600.

Bacmann, J., Dubois, M., 2002. Volatility in emerging stock markets revisited. In: Proceedings of London Meeting, European Financial Management Association.
Batten, J.A., Ciner, C., Lucey, B.M., 2010. The macroeconomic determinants of volatility in precious metals markets. Resources Policy 35, 65-71.

Bayoumi, T., Fazio, G., Kumar, M., MacDonald, R., 2007. Fatal attraction: using distance to measure contagion in goods times as well as bad. Review of Financial Economics 16, 259-273.

Chen, M.H., 2010. Understanding world metals prices-returns, volatility and diversification. Resources Policy 35, 127-140.

Chiang, T.C., Jeon, B.N., Li, H., 2007. Dynamic correlation analysis of financial contagion: evidence from asian markets. Journal of International Money and Finance 26, 1206-1228.

Climent, F., Meneu, V., 2003. Has 1997 Asian crisis increased information flows between international markets? International Review of Economics \& Finance 12, 111-143.

Cochran, S.J., Mansur, I., Odusami, B., 2012. Volatility persistence in metal returns: a FIGARCH approach. Journal of Economics and Business 64, 287-305.

Deng, A., Perron, P., 2008. The limit distribution of the CUSUM of squares test under general mixing conditions. Econometric Theory 24, 809-822.

Diamandis, P.F., 2009. International stock market linkages: evidence from Latin America. Global Finance Journal 20, 13-30.

Engle, R.F., 2002. Dynamic conditional correlation: a simple class of multivariate generalized autoregressive conditional heteroskedasticity models. Journal of Business \& Economic Statistics 20, 339-350.

Engle, R.F., Kelly, B., 2012. Dynamic equicorrelation. Journal of Business \& Economic Statistics 30, 212-228.

Ewing, B.T., Malik, F., 2005. Re-examining the asymmetric predictability of conditional variances: the role of sudden changes in variance. Journal of Banking \& Finance 29, 2655-2673.

Ewing, B.T., Malik, F., 2013. Volatility transmission between gold and oil futures under structural breaks. International Review of Economics \& Finance 25, 113-121.

Forbes, K.J., Rigobon, R., 2002. No contagion, only interdependence: measuring stock market comovements. Journal of Finance 57, 2223-2261.

Gilmore, C.G., Lucey, B.M., McManus, G.M., 2008. The dynamics of central European equity market comovements. Quarterly Review of Economics and Finance 48, 605-622.

Hammoudeh, S., Yuan, Y., McAleer, M., Thompson, M.A., 2010. Precious metalsexchange rate volatility transmissions and hedging strategies. International Review of Economics \& Finance 19, 633-647.

Hillier, D., Faff, R., Draper, P., 2006. Do precious metals shine? An investment perspective. Financial Analysts Journal 62, 98-106.

Inclan, C., Tiao, G.C., 1994. Use of cumulative sums of squares for retrospective detection of change in variance. Journal of the American Statistical Association 89, 913-923.

Jain, A., Ghosh, S., 2013. Dynamics of global oil prices, exchange rate and precious metal prices in India. Resources Policy 38, 88-93.

Kearney, A.A., Lombra, R.E., 2009. Gold and platinum: toward solving the price puzzle. Quarterly Review of Economics and Finance 49, 884-892.

Kokoszka, P., Leipus, R., 2000. Change-point estimation in ARCH models. Bernoulli 6, 513-539.

Kumar, D., Maheswaran, S., 2013. Detecting sudden changes in volatility estimated from high, low and closing prices. Economic Modelling 31, 484-491.

Lavielle, M., 2005. Using penalized contrasts for the change-point problem. Signal Processing $85,1501-1510$

Lavielle, M., Teyssiere, G., 2007. Adaptive detection of multiple change-points in asset price volatility. In: Teyssiere, G., Kirman, A.P. (Eds.), Long Memory in EconomicsSpringer Berlin, Heidelberg.

Markwat, T., Kole, E., Van Dijk, D., 2009. Contagion as a domino effect in global stock markets. Journal of Banking \& Finance 33, 1996-2012.

Mensi, W., Beljid, M., Boubaker, A., Managi, S., 2013. Correlations and volatility spillovers across commodity and stock markets: linking energies, food, and gold. Economic Modelling 32, 15-22.

Mikosch, T. Starica, C. 2004. Nonstationarities in financial time series, the long range dependence and the IGARCH effects. Review of Economics and Statistics 86, 378-390.

Morales, L., Andreosso-O'Callaghan, B., 2011. Comparative analysis on the effects of the Asian and global financial crises on precious metal markets. Research in International Business and Finance 25, 203-227.

Mutafoglu, T.H., Tokat, E., Tokat, H.A., 2012. Forecasting precious metal price movements using trader positions. Resources Policy 37, 273-280.

Nazlioglu, S., Erdem, C., Soytas, U., 2013. Volatility spillover between oil and agricultural commodity markets. Energy Economics 36, 658-665.

Pettenuzzo, D., Timmermann, A., 2011. Predictability of stock returns and asset allocation under structural breaks. Journal of Econometrics 164, 60-78.

Sanso, A., Arago, V., Carrion, J.L., 2004. Testing for changes in the unconditional variance of financial time series. Revista de Economia Financiera 4, 32-53.

Syllignakis, M.N., Kouretas, G.P., 2011. Dynamic correlation analysis of financial contagion: evidence from the central and eastern european markets. International Review of Economics \& Finance 20, 717-732.

Vivian, A., Wohar, M.E., 2012. Commodity volatility breaks. Journal of International Financial Markets, Institutions \& Money 22, 395-422.

Xu, K.L., 2013. Powerful tests for structural changes in volatility. Journal of Econometrics 173, 126-142.

\footnotetext{
${ }^{10}$ Reminder: volatility shift contagion is defined as a significant change in the co-movement of asset returns between consecutive volatility regimes.
} 